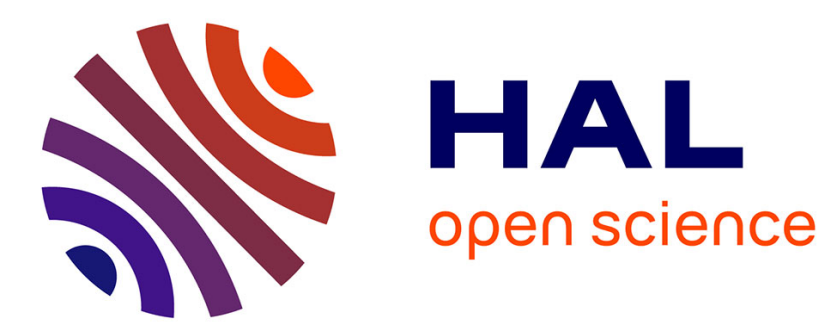

\title{
Local texture measurements with the scanning electron microscope
}

G. Gottstein, O. Engler

\section{To cite this version:}

G. Gottstein, O. Engler. Local texture measurements with the scanning electron microscope. Journal de Physique IV Proceedings, 1993, 03 (C7), pp.C7-2137-C7-2142. 10.1051/jp4:19937339 . jpa00251986

\section{HAL Id: jpa-00251986 https://hal.science/jpa-00251986}

Submitted on 1 Jan 1993

HAL is a multi-disciplinary open access archive for the deposit and dissemination of scientific research documents, whether they are published or not. The documents may come from teaching and research institutions in France or abroad, or from public or private research centers.
L'archive ouverte pluridisciplinaire HAL, est destinée au dépôt et à la diffusion de documents scientifiques de niveau recherche, publiés ou non, émanant des établissements d'enseignement et de recherche français ou étrangers, des laboratoires publics ou privés. 


\title{
Local texture measurements with the scanning electron microscope
}

\author{
G. GOTTSTEIN and O. ENGLER
}

Institut für Metallkunde und Metallphysik, RWTH Aachen, Kopernikusstr. 14, 5100 Aachen, Germany

\begin{abstract}
$\underline{\text { Abstract }}$
Techniques for convenient measurement of the crystallographic orientation of small volumes in bulk samples by electron diffraction in the SEM are discussed. They make use of Selected Area Electron Channelling Patterns (SAECP) and Electron Back Scattering Patterns (EBSP). The principle of pattern formation as well as measuring and evaluation procedure are introduced. The methods offer a viable procedure for obtaining information on the spatial arrangement of orientations, i.e. on orientation topography. Thus, they provide a new level of information on crystallographic texture. An application of the techniques for local texture measurements is demonstrated by an example, namely for investigation of considering the recrystallization behaviour of binary $\mathrm{Al}-1.3 \% \mathrm{Mn}$ with large precipitates. Finally, further developments of the EBSP technique are addressed.
\end{abstract}

\section{Introduction}

The conventional method to determine the crystallographic texture of a material is to measure a set of $\mathrm{X}$-ray pole figures and to compute the orientation distribution function (ODF). This so called macrotexture provides information on the volume fraction associated with each orientation, but not on the location of the individual orientations. For many applications, however, in particular with regard to microstructure evolution during processing or for information about the character of grain boundaries in a polycrystal, information about the local arrangement of orientations (micro-texture) is necessary. This requires determination of orientations in small volumes which are characteristic for the state of the material, for instance within the size of a grain for recrystallized material or within a cell or subgrain in deformed specimens. Commonly, the characteristic dimension for local orientation measurement is in the order of $1 \mu \mathrm{m}$ and thus not accessible with conventional X-ray sources.

With the advent of powerful commercial transmission electron microscopes around 1960 it became possible for the first time to use electron diffraction for texture measurements. The major disadvantages of such techniques in a TEM are, however, the difficult and laborious sample preparation and the very small area of view, which is usually much less than $100 \mu \mathrm{m}$ in diameter.

The first techniques to determine local orientations on bulk specimens by electron diffraction in a SEM were developed around 1970 and are known today as "Selected Area Electron Channelling Patterns" (SAECP) [1,2] and "Electron Back Scattering Patterns" (EBSP) [3-6]. In the following these two techniques will be introduced and compared and their possibilities will be demonstrated by means of an example considering the recrystallization behaviour of a binary alloy $\mathrm{Al}-1.3 \% \mathrm{Mn}$ which contained large precipitates prior to deformation. 


\section{Orientation Determination by Electron Diffraction in the SEM}

\subsection{Principles of Pattern Formation}

An electron beam entering a sample is subject to diffuse scattering towards all directions. Thus, the atomic planes of a crystalline specimen are showered by electrons arriving from all directions and, therefore, also by electrons which obey Bragg's law, $\lambda=2 \cdot d \cdot \sin \theta$ (with $\lambda$ : wave length of the electrons; $d$ : spacing of the crystallographic planes; $\theta$ : Bragg angle) and, therefore, undergo elastic scattering with angle $\theta$. From the schematic diagram (Fig.1a) it is obvious that the reflected electrons that obey Bragg's law, lie on the surface of a cone (Kossel-cone) about the normal of the reflecting atomic planes with opening angle $(\pi / 2-\theta)$. Since the wavelength of the electrons is very small, however, the opening angle of this cone is very large and the line of intersection of the cone with the film plane is essentially straight (Fig.1a). For each set of atomic planes two parallel lines with an angular distance of $2 \cdot \theta$ will form.

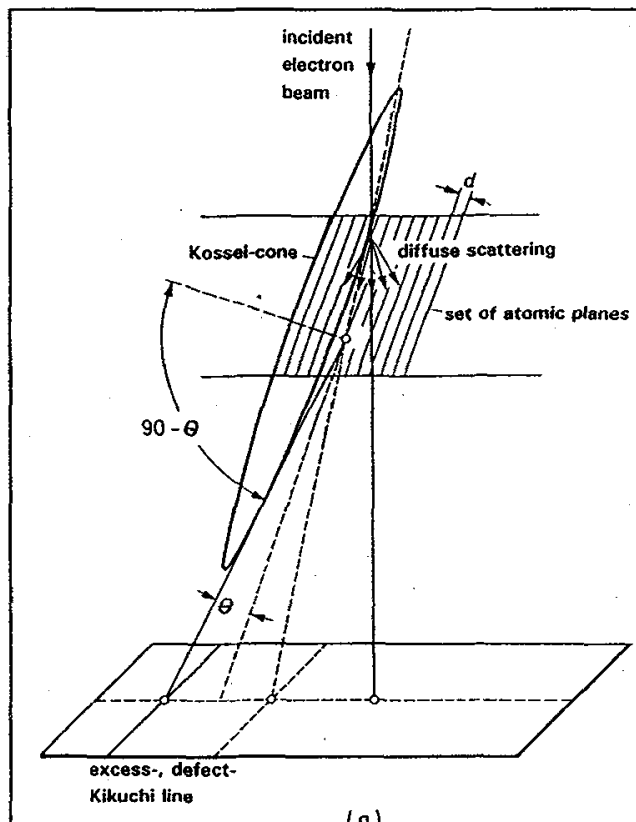

(a)

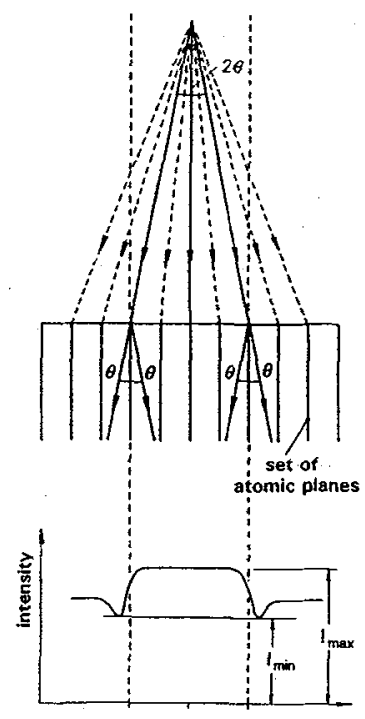

(b)

Fig.1: Formation of Kikuchi lines a) with defect and excess lines, b) with Pseudo Kikuchi bands

(Fig.1a). In contrast to the sharp Kikuchi lines in TEM, however, the pattern in a SEM consists of bands of higher intensity (Pseudo Kikuchi lines, Fig.1b). This is due to further diffuse scattering of the diffracted electrons and the orientation dependent contribution of secondary electrons.

\subsection{SAECP Technique}

In order to get Selected Area Electron Channelling Patterns (SAECP) the electron beam in a SEM is focused on the sample to be examined. At this position the electron beam is tilted by an angle $\alpha$ either in two directions or on concentric cones with $0<\alpha \leq \alpha_{\text {max }}$ (Fig.2a). A band in the SAECP is formed if the Bragg condition is fulfilled, i.e. $\alpha=\theta$ (Fig. $2 b, c$ ). In practical applications, the angle $\alpha_{\max }$ is limited to $\sim 7^{\circ}$ and, therefore, the diameter of the SAECP is restricted to $\sim 14^{\circ}$. Caused by the necessity of eucentric tilting of the electron beam the spatial resolution is limited to $5-10 \mu \mathrm{m}$. The technique is very sensitive to lattice defects, therefore only recrystallized or strongly recovered rather the plastically deformed structures can be analyzed. 


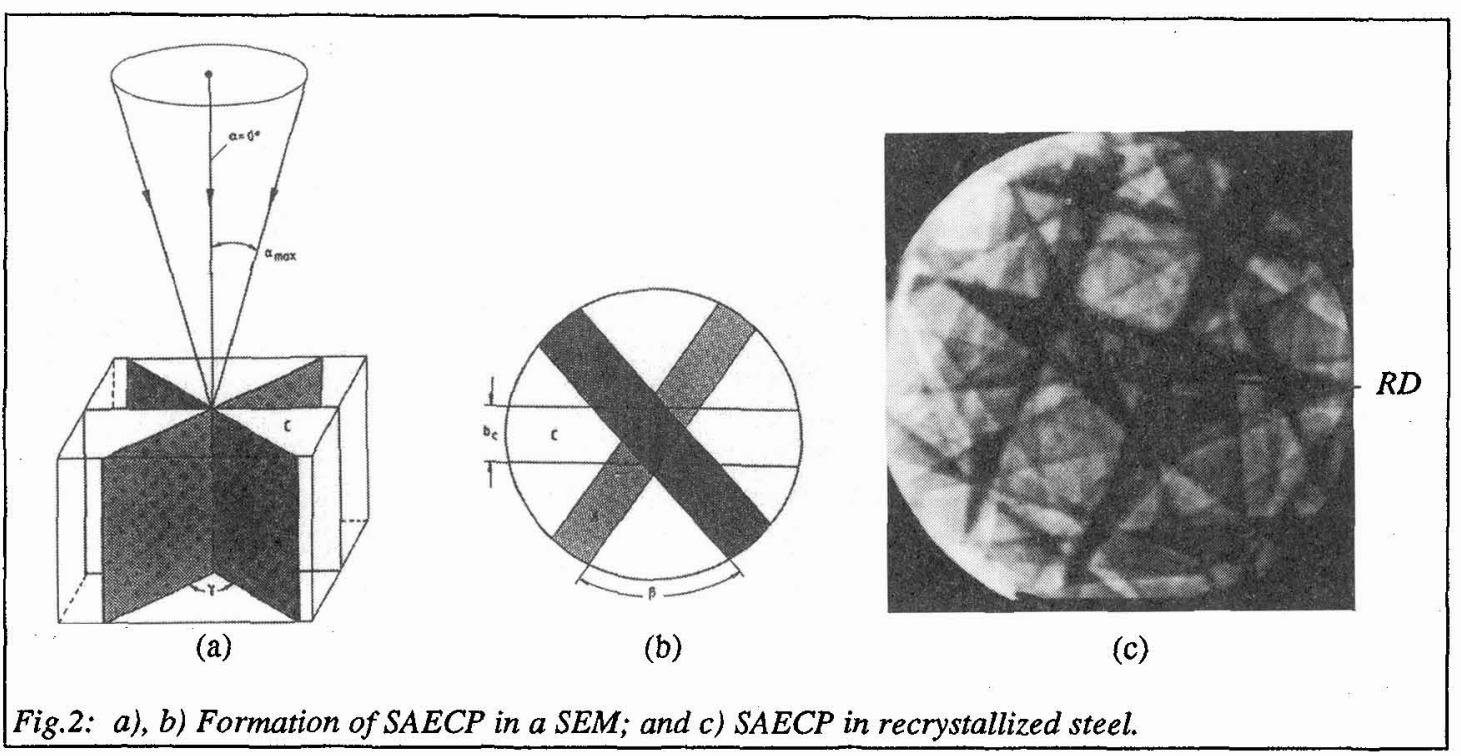

\subsection{EBSP Technique}

To conduct an Electron Back Scattering Pattern (EBSP) measurement the electron beam is focused on the position to be analyzed. The specimen is strongly tilted $\left(60^{\circ}-70^{\circ}\right)$ in order to obtain largest gain of backscattered electrons. The pattern (Fig.3) can be recorded on a film placed in the vacuum chamber. For convenience and on-line measurements, however, nowadays the pattern is usually revealed on a phosphorus screen in the SEM (Fig.4) and can be recorded from the screen through a lead glass window using a low light television camera. In order to improve pattern quality, the information is processed by a camera amplifier and an image processor, e.g. by background subtraction, and is finally output to a monitor or transferred to a computer (Fig.4), for storage and evaluation of the orientation.

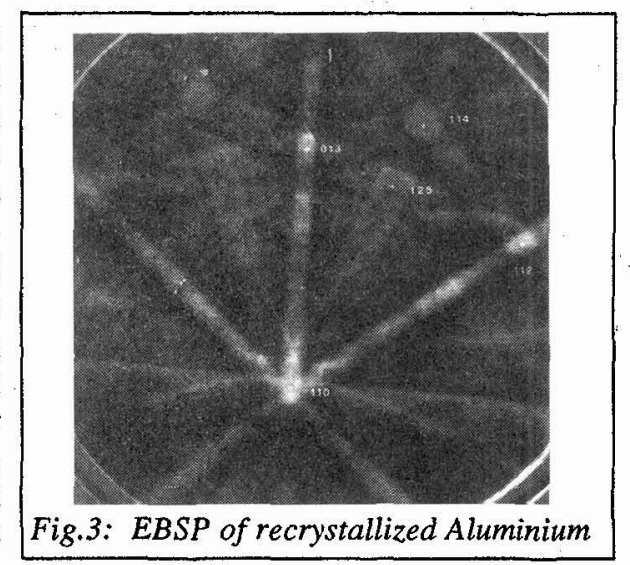

In order to obtain good EBSP contrast in the SEM a high acceleration voltage $(20 \mathrm{kV})$ and a high beam current $\left(10^{-7}-10^{-8} \mathrm{~A}\right)$ are required. Sample preparation is usually easy and can readily be carried out with standard metallographical methods. In order to obtain sufficient pattern quality, however, the sample surface prepared must not show any deformation. Thus electrolytical polishing or slight chemical etching commonly yield best results.

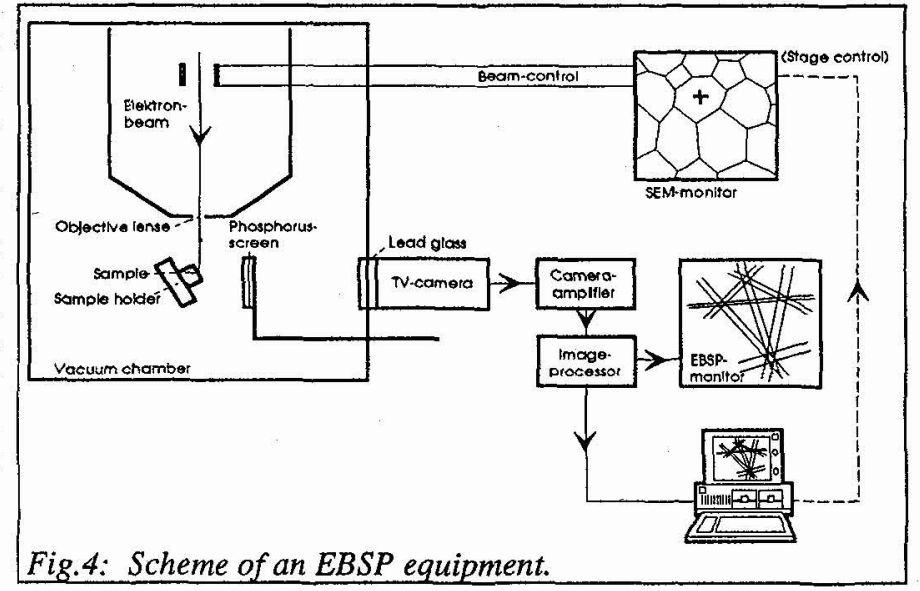




\subsection{Comparison of SAECP and EBSP}

Comparing the advantages and disadvantages of methods of local texture measurement in the SEM [7] it became soon obvious, that the EBSPtechnique is most capable and convenient in analyzing orientations of microscopic volumes on bulk samples (cf. Tab.1). Compared to SAECP, the

\begin{tabular}{|l|l|l|}
\hline & SAECP & EBSP \\
\hline Modifications at the SEM & few & several \\
\hline Spatial resolution & $5-10 \mu \mathrm{m}$ & $<1 \mu \mathrm{m}$ \\
\hline Angular area & $15^{\circ}$ & $70^{\circ}$ \\
\hline Accuracy (relative) & $0.5^{\circ}$ & $0.5^{\circ}$ \\
\hline Sample preparation & polished surface & less critical \\
\hline
\end{tabular}

Tab.1: Comparison of SAECP and EBSP

EBSP stand out by a much higher spatial resolution $(<1 \mu \mathrm{m}$ rather than $5 \mu \mathrm{m})$. This allows to investigate also deformed samples if the structure consists of dislocation cells in excess of this size. For instance, in aluminium cold rolled samples with up to $95 \%$ reduction can be studied by EBSP. The evaluation of the patterns is very much facilitated by the large stereographic angle obtained $\left(70^{\circ}\right.$ compared to $15^{\circ}$ with SAECP, Figs.2c,3). This speeds up evaluation and reduces ambiguity of the orientation.

Furthermore, sample preparation is less critical for EBSP than for SAECP. So, even fracture surfaces can be studied using EBSP.

\subsection{Evaluation of Orientation Data}

The diffraction patterns of both EBSP and SAECP (Figs.2c,3) consist of intersecting bands. Each band has a distinct width and corresponds to a distinct crystallographic plane or zone. Accordingly, an intersection of bands corresponds to a zone axis. By measuring the angles between several zones or zone axes, respectively, and comparison with a look-up table for the corresponding crystal structure the zones or the zone axes can be indexed and the crystallographic orientation of the illuminated microscopic volume can be determined. Furthermore, the width of the bands $b$ (Fig.2b) which e.g. for cubic structures is given by $b \propto \lambda / a \cdot \sqrt{h^{2}+k^{2}+l^{2}}$ (a: lattice spacing) can be used to determine the indices $(h \mathrm{kl})$ of the zones. Equivalently, from the obtained crystallographic information the crystal structure can be verified. For further details of orientation evaluation see [2,8-11].

\section{Application of the EBSP-technique}

The application of local orientation determination by means of EBSP will now be illustrated by an example pertaining to the recrystallization behaviour of particle containing Al-alloys.

In order to understand the recrystallization texture development of particle containing Al-alloys the binary $\mathrm{Al}$-alloy $\mathrm{Al}-1.3 \mathrm{wt} \% \mathrm{Mn}$ was prepared and treated in such a way that large $\mathrm{Al}_{6} \mathrm{Mn}$-precipitates were present prior to cold rolling for $92 \%$ thickness reduction. During recrystallization annealing of such samples nucleation of recrystallization is known to occur at two different sites, namely (i) at the former grain boundaries or transition bands; and (ii) in the deformation zones around the large precipitates (Fig.5; e.g. $[12,13]$ ).

The macrotexture of $\mathrm{Al}-1.3 \% \mathrm{Mn}$ after complete recrystallization $\left(300 \mathrm{~s}\right.$ at $450^{\circ} \mathrm{C}$ ) is shown in Fig.6a in form of the corresponding orientation distribution function (ODF). In comparison to homogeneous Alalloys [13] the texture is quite weak exhibiting a maximum intensity of only $\mathrm{f}(\mathrm{g})_{\max }=8.3$. The texture consists of the Cube orientation $\{001\}<100\rangle$ (visible at $\left.\left(\varphi_{1}, \phi, \varphi_{2}\right)=\left(0^{\circ}, 0^{\circ}, 0^{\circ}\right)\right)$ with strong scatter about the rolling direction RD and the sheet normal direction ND (visible in the ODF by the scatter from $\left(0^{\circ}, 0^{\circ}, 0^{\circ}\right)$ along $\phi$ and $\varphi_{1}$, respectively). Furthermore, a weak orientation $\{011\}<122>$ at $\left(65^{\circ}, 45^{\circ}, 0^{\circ}\right)$, called P-orientation, is observed, which does not occur in pure $\mathrm{Al}$.

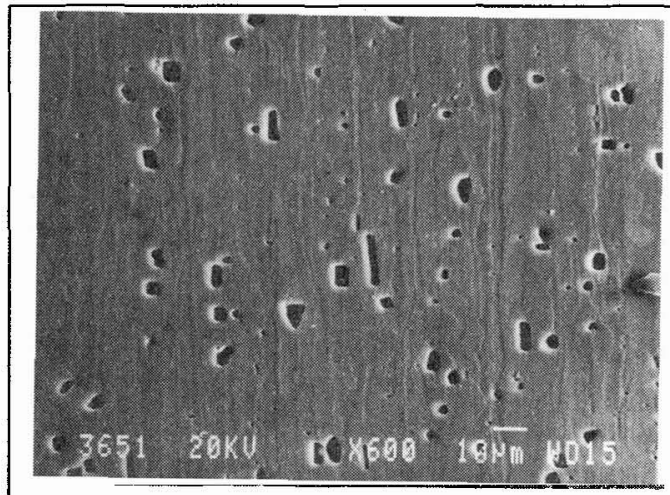

Fig.5: Microstructure of partially recrystallized Al-1.3\% Mn (10s at $\left.450^{\circ} \mathrm{C}\right)$. 
In order to analyze the recrystallization behaviour in more detail, the orientations of the new grains formed during the early stages of recrystallization annealing were determined by means of EBSP and classified into two groups according to their nucleation sites. So, two sets of single grain orientation data were obtained, one for new grains stemming from former grain boundaries or transition bands, and the other for new grains stemming from deformation zones around the large particles. From these data sets ODFs were calculated by associating each orientation with a Gauss-type scattering peak in Euler angle space (half scatter width $\psi_{0}=6^{\circ}$; Fig.6b,c) [14]. A comparison of these ODFs from individual grain data and the corresponding X-ray ODF (Fig.7a) shows that the recrystallization orientations indeed can be classified according to their nucleation sites. The grains, which nucleated at transition bands (Figs. $5,6 \mathrm{~b})$, mainly reveal the Cube orientation with scatter about RD and the transverse direction TD. This texture corresponds to the typical recrystallization texture of homogeneous Al-alloys [13].

However, the grains which nucleated at the deformation zones around the $\mathrm{Al}_{6} \mathrm{Mn}$-precipitates show a slightly different microtexture (Figs.5,6c): The frequency of Cube and RD and TD scattered Cube orientations is weaker, instead some scatter of Cube about ND is observed and additionally the Porientation occurs. Particularly, the sharpness of the microtexture of grains near particles is noticeably weaker than that of the grains originating from the transition bands. This gives evidence that a higher fraction of randomly oriented grains nucleates at the particles.

From these results it can be concluded that nucleation of recrystallization occurs in the deformation zones around the particles as well as in the transition bands at the former grain boundaries. The new grains originating from the transition bands form the Cube texture as known from homogeneous Alalloys. The grains which stem from particles increase the random part of the recrystallization texture. Furthermore, they lead to the observed weak intensities of ND-scattered Cube and P-orientation. This can be explained by preferred growth of grains with a $40^{\circ}<111>$ orientation relationship with respect to the surrounding deformed matrix [13,15].
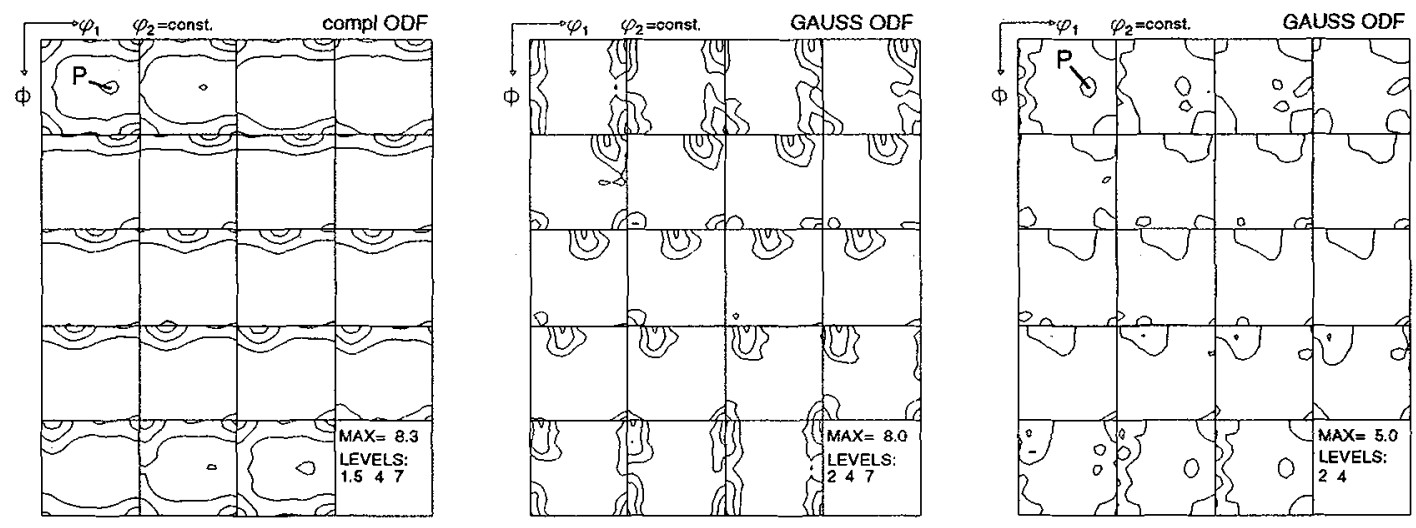

Fig.6: a) X-ray ODF from completely recrystallized sample, b) ODF from new grains stemming from transition bands, c) ODF from new grains stemming from particles. 


\section{Future Trends}

The major deficiency of single grain orientation measurements by EBSP compared to macroscopic texture measurements is the time consuming measurement procedure and therefore, the sampling of usually less than $1 \%$ of the area scanned by X-ray methods. Hence two major improvements of the EBSP systems are necessary, automatic evaluation and automatic specimen scanning.

For an automatic orientation determination a smart pattern recognition code has to be developed. This requires that the entire pattern information recorded by a camera ( $c f$. Sec. 2.3) has to be transferred pixel by pixel to a computer by means of a video grabber card. After contrast enhancement and filtering, the positions of the bands can be determined by pattern recognition methods, e.g. by a Hough transformation $[16,17]$. Then the crystallographic orientation can be computed as described previously. Automatic pattern recognition and evaluation is under development at our institute and has recently been successfully applied to EBSP measurements by other research groups [16,17]. The complete evaluation of a single orientation was reported to take $15 \mathrm{~s}$ (486 PC [16]) or $2 \mathrm{~s}$ (main frame [17]), respectively, compared to approximately 30 s by manual evaluation [11].

Further automation of large scale single grain orientation measurements requires automatic scanning of the selected specimen area with a computer controlled sample stage (Fig.4). Then, an automation of the entire set-up, stage control, pattern recognition and data evaluation, is possible $[17,18]$. With a sampling rate in excess of 1000 orientations per hour large area orientation topography can be obtained. As an example, in Fig.7 the orientation mapping of the microstructure of hot-rolled $\mathrm{Fe}-1 \% \mathrm{Si}$ is shown. From the misorientations between adjacent measurement points, grain boundaries can be revealed and classified according to their character, e.g. indicated by black or dashed lines, if the orientation difference exceeds $10^{\circ}$ or $20^{\circ}$, respectively (Fig.7, [18]). So, large angle grain boundaries, small angle grain boundaries and subgrains can be revealed and evaluated with regard to morphology, orientation correlation, grain boundary character etc.

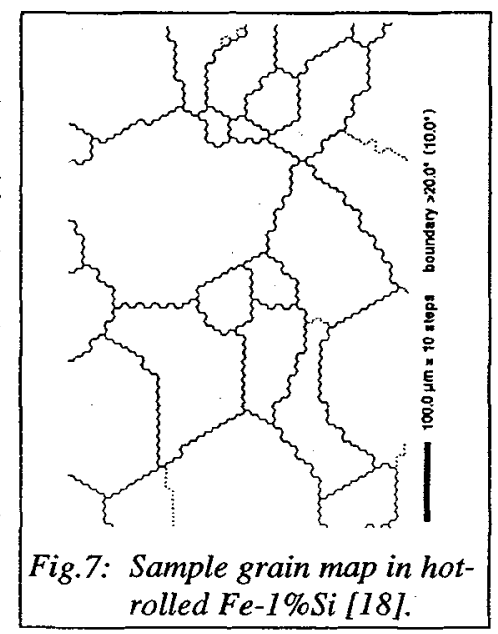

Acknowledgements: The authors wish to thank Mr. P. Yang for making available unpublished results.

\section{References}

1. Van Essen, C.G., Schulson, E.M., Donaghay, R.H., Nature 225 (1970) 847.

2. Lorenz, W., Hougardy, H., Textures and Microstructures 8\&9 (1988) 579.

3. Venables, J.A., Harland, C.J., Phil. Mag. 27 (1973) 1193.

4. Dingley, D.J., Scanning Electron Microscopy II (1984) 569.

5. Hjelen, J., Høier, R., Nes, E., in Proc. XI Int. Conf. on Electron Microscopy, Kyoto, Japan, (1986) Vol.1, p.751.

6. Hjelen, J., Doctoral thesis NTH Trondheim (1990) and Hjelen, J., et al., in Proc. Symp. Microscale Textures, Cincinnati (1991) ASM (in press).

7. Dingley, D.J., Scanning Electron Microscopy IV (1981) 273.

8. Dingley, D.J., Longden, M., Weinbren, J., Alderman, J., Scanning Microscopy 1 (1987) 451.

9. Wright, S.I., Zhao, J.-W., Adams, B.L., Textures and Microstructures 13 (1991) 123.

10. Schmidt, N.H., Bilde-Sørensen, J.B., Juul Jensen, D., Scanning Microscopy 5 (1991) 637.

11. Engler, O., Gottstein, G., steel research 63 (1992) 413.

12. Bleck, W., Bunge, H.-J., Acta metall. 29 (1981) 1401.

13. Engler, O., Lücke, K., Scripta metall. mater. 27 (1992) 1527.

14. Pospiech, J., Lücke, K., Acta metall. 23 (1975) 997.

15. Yang, P., Engler, O., Gottstein, G., submitted to ICOTOM 10, Clausthal (1993).

16. Krieger Lassen, N.C., Conradsen, K., Juul Jensen, D., Scanning Microscopy 6 (1992) 115.

17. Wright, S.I., Adams, B.L., Metall. Trans. 23A (1992) 759.

18. Adams, B.L., Wright, S.I., Kunze, K., Metall. Trans. 24A (1993) 819. 